\title{
Didática no ensino superior: desafios e perspectivas dos docentes de Odontologia da Universidade Estadual de Ponta Grossa
}

\author{
Laína Vochikovski*; Adrieli Burey**; Bianca Medeiros Maran**; Thalita de Paris Matos*; Francine \\ Baldin Able**; Denise Stadler Wambier***; Rita de Cassia Stadler***
}

* Discente de Mestrado, Programa de Pós-Graduação em Odontologia, Universidade Estadual de Ponta Grossa

** Discente de Doutorado, Programa de Pós-Graduação em Odontologia, Universidade Estadual de Ponta Grossa

*** Professora Doutora, Programa de Pós-Graduação em Odontologia, Universidade Estadual de Ponta Grossa

Recebido em 03/07/2017. Aprovado em 09/01/2018.

\begin{abstract}
RESUMO
O objetivo deste trabalho foi avaliar a percepção de docentes do curso de Odontologia quanto as principais dificuldades enfrentadas e as habilidades imprescindíveis para o exercício do magistério superior. Para tal, foi realizada uma pesquisa qualitativa com 47 professores do curso de Odontologia da Universidade Estadual de Ponta Grossa, divididos em dois grupos: a) tempo de atuação docente inferior a 5 anos; b) tempo de atuação docente maior que 5 anos. Após a validação do questionário, este foi encaminhado para os participantes da pesquisa responderem questões abertas sobre o exercício do magistério no ensino superior. Posteriormente à coleta dos dados, foi feita a análise descritiva das informações, exploração do material e interpretação dos resultados. Nos desafios enfrentados, os docentes com mais de 5 anos de atuação citaram a responsabilidade em formar um profissional, dificuldade em motivar os alunos e aquisição de segurança para docência como os principais. Por outro lado, docentes com atuação inferior a 5 anos apontaram o relacionamento com o aluno, insegurança profissional e obtenção do equilíbrio entre a teoria e a prática como principais desafios. Com relação às dificuldades enfrentadas atualmente, as respostas foram semelhantes para os dois grupos, sendo a falta de interesse dos alunos, falta de infraestrutura e de material de apoio para ministrar as aulas, as mais citadas. As habilidades mais mencionadas pelos professores como essenciais para o exercício da profissão incluíram a paciência, didática e necessidade de constante atualização. Pôde-se concluir que os professores enfrentam dificuldades na prática docente, independentemente do tempo de atuação.
\end{abstract}

Descritores: Educação em Saúde. Educação Superior. Educação em Odontologia. 


\section{INTRODUÇÃO}

Refletir sobre os desafios que a docência apresenta no ensino superior é importante para que o professor, ao desempenhar sua função, possa entendê-la de maneira clara e consiga uma melhor atuação. Além dos desafios lançados pela instituição, os quais exigem qualificação, preparação e boa atuação, talvez o maior seja a preocupação e a necessidade do profissional, atuante na área do magistério, desenvolver sua própria identidade ${ }^{1-3}$.

Questões como "por que ser professor universitário e qual o papel deste docente", devem ser analisadas por quem deseja desempenhar essa função, para que possa começar a construir sua identidade como professor ${ }^{4}$. Outro questionamento lançado é se ser professor depende do aprendizado, de uma escolha ou de um dom. No entanto, para esta questão não há uma única resposta. Parte-se do pressuposto de que, a partir da escolha em ser docente, do exercício da profissão, aprenda-se como ser professor e que, com o avançar do conhecimento e das experiências adquiridas, rompa-se a perspectiva da docência como pura vocação ou dom inato. Assim que, respostas a esses questionamentos são encontradas, cabe ao indivíduo tratar-se como professor e agir como tal, fazer de sua aula uma coreografia na qual seus alunos consigam acompanhar os passos e, juntamente com o professor, prosseguir com o "show" ", Exatamente, a palavra show dá lugar a palavra aula, pois, parafraseando Zabalza $(2004)^{5}$, os professores são coreógrafos dos alunos no ambiente de aprendizagem, conduzem o ensinamento aos seus pupilos, assim como um coreógrafo conduz uma dança. Entretanto, o show só se realiza com a colaboração e envolvimento de todos ${ }^{6}$.

A docência no ensino superior é mediada pelas funções do ensino, pesquisa e extensão, sem estas não se faz um professor universitário.
No entanto, não se deve estagnar apenas nesse tripé, pois ensinar é comunicar, dinamizar e, assim como Nóvoa (2007) ${ }^{7}$ citou em "Desafios do trabalho do professor no mundo contemporâneo", ensinar vai além, uma vez que o docente não deve se posicionar no senso comum, apresentando as mesmas aulas diariamente, baseando-se nas mesmas estratégias observadas em seus próprios professores em outras situações e realidades ou, deixar-se convencer por opiniões alheias de que os alunos não se interessam.

Basear-se em experiências vividas por outros professores, pais, colegas ou até de experiências passadas, não é ruim, pelo contrário, são fatores que engrandecem a formação de um professor, o constroem, porque conviver com pessoas e compartilhar tais experiências amplia a bagagem de conhecimentos. Entretanto, é preciso que, além disso, o professor alie seus conhecimentos ao maior número de ferramentas possível, que estabeleça diálogos, dinâmicas, questionamentos. É necessário, pois, que seja uma ponte entre o conhecimento e o aluno, instigando-o a procurar respostas, a valorizar a dúvida, o espanto, a curiosidade e, acima de tudo, estimulando o estudante a pensar ${ }^{8}$.

$\mathrm{O}$ professor ensina a partir de sua experiência enquanto aluno, inspirado em seus antigos professores. [...] alicerça-se nas práticas historicamente construídas, delineando representações da profissão de professor que se estabelecem no senso comum. É um processo bastante presente na docência universitária, já que o professor desse nível de ensino, não tendo, geralmente, formação profissional para o magistério, tende a repetir práticas naturalizadas na sua cultura ${ }^{9}$.

Contudo, é preciso que o professor supere as dificuldades que a prática docente apresenta, as quais parecem estar mais presentes no início de sua trajetória profissional ${ }^{1,2}$; havendo a 
necessidade de se explorar a situação do docente universitário e detalhes do seu trabalho cotidiano, para que se possa contribuir para a melhoria da formação ofertada neste nível de ensino. Além disso, outros grandes desafios da educação superior estão relacionados a problemas que o Brasil enfrenta, tais como: a ampliação do acesso e maior equidade nas condições do acesso; formação com qualidade; diversificação da oferta de cursos e níveis de formação; qualificação dos profissionais docentes; garantia de financiamento, especialmente para o setor público; empregabilidade dos formandos $\mathrm{e}$ egressos; relevância social dos programas oferecidos; e estímulo à pesquisa científica e tecnológica ${ }^{10}$. A superação destas dificuldades pode ser feita por meio de questionamentos sobre o início da experiência docente, sobre quais são as divergências entre os com maior tempo e menor tempo de atuação na vivência e na prática da profissão, além das relações entre os diferentes agentes (instituição, alunos e professor) no processo de formação profissional $^{11}$.

Para isto, o presente estudo teve por objetivo avaliar, por meio de um questionário com perguntas abertas, a percepção de docentes do curso de Odontologia da Universidade Estadual de Ponta Grossa, quanto às principais dificuldades enfrentadas e às habilidades imprescindíveis para o exercício do magistério superior. Os professores foram divididos em dois grupos: a) com tempo de docência inferior a 5 anos e b) superior a cinco anos; realizando uma análise descritiva e comparativa das respostas recebidas pelos os dois grupos.

\section{METODOLOGIA}

\section{Participantes}

Este estudo foi aprovado por meio do parecer $n^{\circ} 1.616 .341$ pela Comissão de Ética em Pesquisa (COEP), da Universidade Estadual de
Ponta Grossa. Após a assinatura do termo de consentimento livre e esclarecido (TCLE), participaram do estudo quarenta e sete docentes do curso de graduação em Odontologia da Universidade Estadual de Ponta Grossa, sendo dez docentes com menos de 5 anos atuando na docência do ensino superior e trinta e sete docentes com tempo superior a esse. Para explicar os objetivos da investigação, houve um contato prévio com os professores para solicitar sua colaboração no preenchimento do questionário e agendar a coleta de dados. Foram incluídos no estudo os que concordaram em participar da pesquisa e os que tiveram disponibilidade de tempo e facilidade de contato.

\section{Instrumento e procedimentos}

Para a realização de uma pesquisa qualitativa, foi feita uma investigação prévia para identificar as dificuldades dos professores no ensino superior, e então um questionário foi elaborado. Para a classificação do tempo de atuação do professor, em menos de 5 anos ou mais de 5 anos na docência do ensino superior, foi adicionado ao final do questionário um item, no qual o professor deveria assinalar o tempo de atuação correspondente. O questionário foi validado por especialistas, sendo realizadas pequenas alterações, seguindo-se a orientação dos avaliadores. Após as adequações, o questionário foi finalizado para ser aplicado no estudo.

O questionário abordou aspectos relacionados aos desafios e as perspectivas da didática no ensino superior com questões abertas, sendo elas: 1) Quais os maiores desafios encontrados por você, quando do momento de realizar a passagem entre a posição de dentista, e, agora, a de professor de uma Instituição de Ensino Superior?; 2) Quais as maiores dificuldades que um professor de ensino superior do curso de Odontologia enfrenta?; 3) Cite três 
habilidades imprescindíveis para se exercer o magistério no ensino superior; 4) Quantos anos atuando como docente na Universidade? Buscou-se abordar o tema de interesse, oferecendo liberdade ao participante para que construísse uma narrativa, associando temas que são relevantes em sua experiência pessoal.

Os docentes participantes foram identificados pela letra $\mathrm{D}$, seguida do número correspondente à ordem cronológica da participação e, por fim, da letra indicando tempo de docência no ensino superior sendo a letra "a" indicativa de menos de 5 anos e a letra "b" mais de cinco anos. Assim, exemplificando, D3a refere-se ao terceiro docente a preencher o questionário no grupo de professores com menos de 5 anos de docência e D2b refere-se ao segundo docente a preencher o questionário no grupo de professores com mais de 5 anos de atuação.

Após a coleta dos dados e transcrição dos questionários, as informações foram analisadas de forma descritiva, pelo tema do conteúdo, fazendo-se uma pré-análise por meio da leitura geral do material, posteriormente uma exploração do material, fazendo a classificação em categorias e, por fim, o tratamento e interpretação dos resultados obtidos $^{12}$.

\section{RESULTADOS}

A amostra foi composta por 47 docentes de uma instituição pública com média de idade de 46,8 anos. As características são apresentadas na tabela 1 .

Tabela 1. Características dos participantes

\begin{tabular}{|c|c|c|}
\hline Variável & & $\begin{array}{c}\text { Número de } \\
\text { docentes }\end{array}$ \\
\hline \multicolumn{3}{|l|}{ Tempo de atuação como professor } \\
\hline & Menos de 5 anos & 10 \\
\hline & Mais de 5 anos & 37 \\
\hline \multicolumn{3}{|l|}{ Gênero } \\
\hline & Feminino & 22 \\
\hline & Masculino & 25 \\
\hline \multicolumn{3}{|l|}{ Titulação } \\
\hline & Mestrado & 10 \\
\hline & Doutorado & 36 \\
\hline & Livre docência & 01 \\
\hline \multicolumn{3}{|l|}{ Carga Horária } \\
\hline & 20 horas & 08 \\
\hline & 40 horas & 12 \\
\hline & Dedicação exclusiva & 27 \\
\hline \multicolumn{3}{|l|}{ Disciplina lecionada } \\
\hline & Dentística & 9 \\
\hline & Prótese & 7 \\
\hline & Periodontia & 5 \\
\hline & Odontopediatria & 4 \\
\hline & Saúde Coletiva & 4 \\
\hline & Endodontia & 3 \\
\hline & Cirurgia & 3 \\
\hline & Clínica Integrada & 2 \\
\hline & Oclusão & 2 \\
\hline & Ortodontia & 2 \\
\hline & Patologia & 2 \\
\hline & Implantodontia & 1 \\
\hline & Microbiologia & 1 \\
\hline & Farmacologia & 1 \\
\hline & Radiologia & 1 \\
\hline
\end{tabular}


Após a análise das respostas dos sujeitos participantes da pesquisa, suas concepções em relação à docência no ensino superior foram organizadas e interpretadas. Em cada pergunta foram transcritos relatos com o objetivo de exemplificar as respostas mais frequentes e/ou as mais divergentes.

1. Quais os maiores desafios encontrados por você, quando do momento de realizar a passagem entre a posição de dentista e, agora, a de professor de uma Instituição de Ensino Superior?

No grupo dos professores com mais de cinco anos de atuação, as respostas foram diversificadas, com relatos inclusive de não terem tido dificuldade na transição. Entre os desafios citados estão: a responsabilidade em formar um profissional, a motivação dos alunos para realização da humanização na odontologia, a concretização do processo ensinoaprendizagem e a e a aquisição de segurança no trabalho que está sendo desenvolvido.

D7b: "Nenhuma dificuldade. Adorei a transição."

D10b: "Motivar os discentes no que diz respeito à humanização em Odontologia."

D17b: "Um dos maiores desafios é sempre pensar em dar uma boa aula, conseguir com que ocorra o processo ensino-aprendizagem."

D22b: "O domínio de uma classe de alunos é algo bastante desafiador, seja em relação ao comportamento, à manutenção da atenção ou ao processo de ensino e aprendizagem em si."

D28b: "Responsabilidade, medo de não ser capaz."

D36b: "Os desafios foram relacionados à mudança de cidade (estado); adaptação às normas."
Por outro lado, as respostas dos profissionais com menos de 5 anos de atuação foram mais semelhantes entre si, pontuando principalmente o relacionamento com o aluno, no que diz respeito ao estabelecimento de uma hierarquia para possibilitar ao professor cobrança e respeito. Além disso, citaram a insegurança e a obtenção do equilíbrio entre a teoria e a prática e o grau de exigência o aluno.

D2a: "Acredito que foi achar o ponto de equilíbrio entre a cobrança/exigência de aprendizado e o relacionamento pessoal com os alunos."

D5a: "Minha maior dificuldade foi me colocar em um nível de hierarquia capaz. de cobrar atitudes e ser respeitado."

D7a: "Ter o respeito dos alunos, uma vez. que eu tinha quase a mesma idade deles." D9a: "Acredito que a insegurança seja uma dificuldade importante nesse momento de transição principalmente porque é o momento que a sua maneira de expor o conteúdo será testada na prática. Além disso, o iniciante acredita que é seu dever conhecer tudo sobre os assuntos abordados, algo que só o tempo desconstruirá, visto que o aprendizado é uma constante."

D11a: "Passar o conhecimento sem parecer banal."

Analisando as respostas observou-se diferença entre os relatos dos docentes com mais ou menos tempo de experiência. Para os docentes mais experientes os principais desafios estão relacionados com resultado esperado da sua atuação, ou seja, o processo ensinoaprendizagem formando profissionais capacitados e com visão humanizada da odontologia. Já os professores menos experientes apontaram desafios relacionados com a atuação em si, no que diz respeito ao relacionamento com o aluno na sala de aula e a obtenção de equilíbrio 
entre a teoria e a prática. $\mathrm{O}$ desafio citado por ambos os grupos foi a obtenção de segurança no trabalho.

\section{Quais as maiores dificuldades que um professor de ensino superior do curso de Odontologia enfrenta?}

Verificou-se, por meio das respostas dos participantes, que os obstáculos enfrentados por quem tem mais ou menos tempo de docência são muito semelhantes. Citaram como os dois principais: a falta de interesse dos alunos e a falta de infraestrutura adequada e de material de apoio para ministrar as aulas. Uma dificuldade relatada, bem específica da área odontológica, diz respeito a conseguir formar um profissional que alie o conhecimento teórico com a habilidade manual. Outros pontos discutidos pelos docentes foram o número de alunos em cada turma e a dificuldade de comunicação. Apenas um professor disse não ser capaz de responder a esse questionamento.

D5a: "É o ambiente fisico como falta ou limitação de salas de aulas, falta de manutenção dos equipamentos de trabalho."

D6a: "Falta de capacidade de transferir a teoria para a prática, eles acham que a matéria que já concluíram nunca mais será necessária. Não conseguem fazer a união dos conhecimentos das diversas disciplinas e não conseguem levar isso para prática. Para eles, é tudo muito abstrato. Nivel dos alunos muito diferentes. Falta de recurso financeiro para aquisição de equipamentos necessários."

D7a: "Fazer os alunos entenderem que as disciplinas do curso não são inertes, independentes ou estáticas uma vez que têm relação direta com o atendimento de outro ser humano."

D9a: "Como a odontologia é uma área do conhecimento que exige prática, conciliar o conteúdo teórico e a pesquisa com a habilidade manual da clínica torna-se um desafio. Para a Saúde Coletiva, que é minha área de atuação, os desafios na odontologia são ainda maiores, já que o desinteresse dos alunos é observado rotineiramente, uma vez que trata de assuntos que fogem dessa prática clínica tão reverenciada pelos acadêmicos.",

D2b: "Falta de material de apoio para ministrar as aulas, desinteresse por parte de uma grande parte dos alunos."

D3b: "A maior dificuldade não é fazer com que os alunos aprendam, acho que esse não é o ponto maior. A maior dificuldade que se tem hoje é fazer com que os alunos adquiram competência para o desenvolvimento das atividades. Fazer o aluno aplicar aquilo que ele aprendeu, adquirindo competências e habilidades para resolver os problemas que ele vai se deparar, para que ele não precise de um professor pra poder falar o que ele tem que fazer."

D7b: "Falta de recursos financeiros $e$ infraestrutura adequada."

D18b: "Infraestrutura devido à falta de condição de trabalho."

D27b: "O controle comportamental do aluno. Deficiência na formação básica."

\section{Cite três habilidades imprescindíveis para se exercer o magistério no ensino superior.}

Independentemente do tempo de atuação, as habilidades mais citadas pelos docentes como essenciais para o exercício da profissão foram a paciência, a didática, o conhecimento, a comunicação e a necessidade de constante atualização. Além disso, também foram citadas: a criatividade, o bom relacionamento com o 
aluno, a clareza e atratividade para transmitir o conhecimento, a humildade e com isso não ter medo de errar, perseverança, carisma, e capacidade de correlacionar às disciplinas.

D1a: "Paciência, boa comunicação, criatividade."

D2a: "Integrar disciplinas correlatas, transmitir conhecimento de forma clara e acessivel aos alunos, disponibilidade de se manter sempre atualizado."

D4a: "Paciência, didática, ter boas relações interpessoais (aluno e com o corpo docente)."

D11a: "Paciência, capacidade de comunicação e gosto pelo estudo."

D2b: "Não ter medo do erro, tentar colocar práticas docentes que estimulem a autonomia do aluno, tentando conciliar de forma efetiva os pilares: ensino, pesquisa e extensão."

D4b: "Paciência, didática, vontade de estar sempre estudando e aprendendo."

D10b: "Dedicação para querer sempre se atualizar, saber entender as diferenças individuais dentro de uma única sala, fazer a aula atraente até para os que realmente não se identificam com a matéria e ser criativo."

D18b: "Paciência, perseverança, tolerância."

D31b: "Conhecimento pleno da área ministrada. Didática e vontade de ensinar. Integração, sensibilidade $e$ paciência com os alunos."

\section{DISCUSSÃO}

A consolidação relativamente recente da pós-graduação nas universidades brasileiras tem despertado interesse nos docentes com formação avançada a se dedicarem mais a pós-graduação, deixando a graduação aos docentes mais jovens e menos titulados. Em vista disso, a graduação passou a sofrer desprestígio e desconsideração pelos docentes mais experientes e muitas vezes mais preparados ${ }^{13}$.

Assim, ambos os grupos, com maior ou menor tempo de docência, têm enfrentado desafios na prática profissional, as vezes pelo despreparo de docentes mais jovens, pela saturação de alguns docentes com maior experiência, ou ainda pela tarefa cada vez mais desafiadora de ser professor universitário no Brasil, pelo momento de incerteza que o país tem passado e das diferentes expectativas criadas pelo ambiente educacional moderno $\mathrm{e}$ transformador ${ }^{13-15}$.

Segundo Guarnieri, em 2005 ${ }^{16}$, numa perspectiva crítica o início da docência é visto como um choque com a realidade, principalmente em relação aos conteúdos curriculares e aos alunos, gerando uma forte insegurança. Nóvoa, (2007) ${ }^{7}$, afirmou que o primeiro desafio do docente no ensino superior é colocar em prática a ideia de uma melhor organização da profissão docente, ou seja, o professor frente a uma sala de aula associado aos olhares atentos dos alunos aos seus movimentos.

No presente estudo, quando os docentes foram questionados sobre quais os maiores desafios encontrados no momento da passagem da posição de aluno para a de professor, foram observadas divergências nas respostas dos professores com menos de cinco anos de docência no ensino superior comparadas aos professores com mais de 5 anos de docência. $\mathrm{O}$ grupo mais jovem relatou dois pontos principais: o encontro do equilíbrio entre a teoria e a prática e o nível de hierarquia entre professor-aluno. Esse equilíbrio teórico-prática é desafiante para o professor, pois Lisita, (2006) ${ }^{17}$, já afirmava que o ensino é uma atividade teórico-prática transformadora da realidade, melhor dizendo, é necessário analisar o que acontece com o ensino dentro e fora da sala de aula e como ele se 
relaciona com o a função social do trabalho.

$\mathrm{Na}$ área odontológica, esse desafio torna-se ainda maior, pois o aluno desde o início precisa dessa junção teórico-prática nas atividades teóricas, laboratoriais e clínicas, para que, assim, os profissionais formados possam estar habilitados em exercer a pesquisa e suas funções na prática odontológica, baseados no que aprenderam na teoria ${ }^{18}$. Fernandes e colaboradores, $(2003)^{19}$, afirmaram que as ações pedagógicas devem encontrar esse equilíbrio para estimular docentes e discentes a buscarem novos conhecimentos em resposta às questões colocadas pela prática.

Outro ponto importante relatado pelos docentes neste estudo é o estabelecimento do nível de hierarquia. Do ponto de vista pedagógico, os educadores não devem apenas instruir, mas estimular o aluno a tomar decisões e fazer observações, sendo o professor um facilitador do estudante, para que este desenvolva habilidades e atitudes. "O que não se pode é perder de vista as diferenças de saber entre esses dois sujeitos do aprendizado (hierarquia natural professor-aluno) ${ }^{20}$."

Por outro lado, para o grupo de professores com mais de cinco anos na docência, um item importante observado foi a responsabilidade de formar profissionais. Pode-se dizer que essa responsabilidade do professor é a capacidade de formar pessoas para produzirem conhecimento e torná-lo acessível à sociedade ${ }^{21}$.

Já quando avaliada as respostas entre os grupos deste estudo, observou-se a palavra insegurança relatada por alguns docentes. Essa insegurança, em geral, acontece no momento em que o conteúdo exposto será testado na prática. Isaia \& Bolzan $(2008)^{22}$ observam algumas percepções marcantes no período de passagem professor-aluno, como: solidão pedagógica, insegurança frente aos alunos e à disciplina, tanto em termos de manejo de classe, quanto de domínio do conteúdo da disciplina. A insegurança frente aos alunos ou à disciplina é uma característica comum no início da carreira, devido ao despreparo dos professores para a docência superior, visto que, quando há este preparo, ele está presente na forma de disciplinas esparsas nos cursos de graduação e na pósgraduação "lato ou stricto sensu", e, ainda, quando ocorre, é dado na forma de estágio docente, uma preparação superficial para docência no nível superior. Pode-se dizer, assim, que essa insegurança, relatada pelos docentes, está atrelada tanto pela falta de experiência quanto pela falta de suporte e embasamento teórico que lhe garantam segurança frente ao desafio do processo de ensino aprendizagem.

E quando os docentes foram questionados sobre as maiores dificuldades que um professor de ensino superior enfrenta, verificou-se uma associação das respostas com a primeira questão, como, o equilíbrio entre a técnica e a prática, observando que, além de ser um desafio inicial, essa dificuldade persiste ao longo do tempo na prática docente.

Outra resposta dada pelos docentes foi o desinteresse dos alunos, o que vai ao encontro dos resultados obtidos na pesquisa realizada por Franco (2013) ${ }^{23}$, na qual a maioria dos professores entrevistados também cita o desinteresse discente, que pode ser atribuído à falta de preparo dos alunos para acompanhar as aulas. Em seu estudo Franco ressalta algumas falas dos professores, como: "os alunos não sabem mais escrever, não conseguem comunicar suas ideias"; "eles não sabem o que estão fazendo na universidade! A maioria não lê, não estuda e nem quer aprender". Esse desinteresse pode ser devido à abertura de novas vagas e novos cursos, o que resulta em professores exaustos e com uma nova realidade: alunos que não tiveram oportunidades de se fazerem leitores, se tornarem críticos, e buscarem a ciência de forma 
interessada, como relata Charlot em 2006 ${ }^{24}$. Todavia, é importante ressaltar que o ensino também é caracterizado pela função do professor em despertar no aluno o interesse para buscar mais informações ${ }^{25}$.

Oliveira (2006) ${ }^{26}$ chama o desinteresse e desmotivação dos alunos, como um "mal-estar" docente, relacionado ao ambiente profissional do professor. Dito isso, associamos, com outra dificuldade encontrada pelo docente neste estudo, que foi o ambiente físico e falta de recursos. $\mathrm{O}$ docente estando presente em ambiente de trabalho deficiente, falta de recursos humanos e materiais, violência nas salas de aulas e esgotamento físico, vai favorecer a um desgaste psicológico do educador ${ }^{27}$. Nesta resposta devemos considerar que a pesquisa foi conduzida em uma universidade pública, que tem uma maior precarização do trabalho, desvalorização da imagem do professor, baixos salários e carência de recursos materiais. Todas estas situações configuram fatores que podem gerar sobrecargas de trabalho físico e mental, trazendo consequência na satisfação, saúde e bem-estar dos docentes e discentes ${ }^{28}$.

$\mathrm{Na}$ questão relacionada às habilidades no exercício do magistério no ensino superior, a palavra mais citada foi "paciência", visto que, essa não é uma habilidade e sim um substantivo, uma qualidade, uma virtude a ser praticada pelo docente, pois como já citado acima, são vários os fatores que interferem negativamente no processo de ensino e de aprendizagem. Alguns professores entrevistados relataram mais suas características do que propriamente habilidades que, segundo Goldberg (1974) ${ }^{29}$, é a capacidade de saber fazer alguma coisa por meio de ações ordenadas para a realização de um objetivo. Tal capacidade é desenvolvida por meio do aprendizado de técnicas, métodos, regras, estratégias, exercícios e treinamento, que pode ser oriunda de características pessoais inatas ou desenvolvidas. Portanto, paciência é uma característica pessoal que auxilia no desenvolvimento de determinadas habilidades, como por exemplo "transmitir o conhecimento de forma clara", segundo D2a.

Outra habilidade citada pelos entrevistados foi a didática, imprescindível para um docente do ensino superior. Didática é "a ciência e a arte do ensino" 30 . Como arte, a didática não objetiva apenas o conhecimento, mas procura aplicar os seus próprios princípios na instrução educativa. Outras respostas relacionadas à didática neste estudo foram: "fazer aula atraente até para os que não se identificam com a matéria" e "didática para a construção do conhecimento" (D5b). O professor precisa levar em conta o meio em que o aluno vive e adaptar-se a ele, buscando sua cultura e sua realidade ${ }^{31}$. Para isso, é necessária muita criatividade, outra habilidade citada pelos docentes entrevistados, imprescindível para todo profissional que não quer tornar seu dia a dia uma rotina enfadonha e sem propósito, além da criatividade, ressalta-se também a transferência do conhecimento, ou seja, a transposição didática, pois o professor não pode simplesmente reproduzir os conteúdos dos programas de formação ${ }^{32}$.

Santos $(2010)^{33}$ ressalta que a prática correta do professor do ensino superior deve estar sustentada por três pontos principais: conteúdo da área na qual é especialista; sua visão de educação, de homem e de mundo; e as habilidades e conhecimentos que lhe permitam uma ação pedagógica efetiva em sala de aula. Assim, habilidade, segundo o dicionário, é a "qualidade daquele que é hábil; capacidade, destreza, agilidade: ter habilidade para trabalhos manuais" 34 . Essa conceituação vai ao encontro do que o autor Perrenoud (1999) ${ }^{35}$ escreve, quer seja, habilidade trata-se de uma sequência de modos operatórios, uma série de procedimentos mentais que o indivíduo aciona para resolver uma 
situação real, onde ele precise tomar uma decisão. Na área odontológica podemos citar como exemplo, quando um aluno de odontologia está aprendendo a restaurar um dente utiliza a habilidade de trabalho manual que ele já possui, para devolver a anatomia à este dente.

Dessa maneira, com base nesse estudo, tem-se a intenção de levar as dificuldades apontadas pelos professores, às reuniões do departamento de Odontologia da Universidade, para que todos tenham conhecimento e em conjunto elaborarem estratégias para melhorar os desafios encontrados.

Assim, com esse estudo, verificou-se a importância do papel docente no ensino superior, que segundo Zabalza (2004) ${ }^{5}$, deve ser feita a junção de três dimensões: dimensão profissional, como a construção da identidade e os dilemas do exercício profissional; dimensão pessoal, fontes de satisfação e insatisfação no trabalho que acompanham os docentes, situações e problemas pessoais que acompanham o exercício; e dimensão administrativa: condições contratuais, incentivos e obrigações vinculadas à atuação profissional.

\section{CONCLUSÃO}

Com este estudo, pela análise dos questionários, observou-se que os professores sentem dificuldades na prática docente, mesmo professores com mais tempo de docência. Percebeu-se, também, a necessidade do professor em se manter sempre atualizado, sendo a capacitação docente para formar educadores e não especialistas como forma de diminuir a insegurança que muitos professores relataram como um desafio na docência do ensino superior.

\footnotetext{
ABSTRACT

Didactics in higher education: challenges and perspectives of Dentistry teachers of the State University of Ponta Grossa
}

The objective of this study was to evaluate the perception of teachers of the Dentistry course regarding the main difficulties faced and the skills essential for the exercise of the higher education teaching profession. For that, a qualitative research was carried out with 47 professors of the Dentistry course at the State University of Ponta Grossa, divided into two groups: a) less than 5-year teaching experience; b) over 5-year teaching experience. After the validation of the questionnaire, it was sent to the participants of the research to answer open questions about teaching in higher education. After data collection, a descriptive analysis of the information, exploration of the material and interpretation of the results were carried out. Among the challenges faced, teachers with more than 5 years of work experience cited the responsibility to train a professional, difficulty motivating students and developing selfconfidence for teaching as the main points. On the other hand, teachers with less than 5 years of experience pointed out the relationship with the student, professional insecurity and obtaining a balance between theory and practice as the main challenges. With regard to the difficulties currently faced, the responses were similar for the two groups, namely, students' lack of interest, lack of infrastructure and support material to teach classes were the most cited. The most mentioned skills by the teachers as essential to the practice of the profession included patience, didactics and the need for constant updating. The results led to the conclusion that teachers face difficulties in teaching practice regardless of the time of performance.

Descriptors: Health Education. Higher Education. Education in Dentistry.

\section{REFERÊNCIAS}

1. Cunha MID, Boéssio Atrib Zanchet BM. A problemática dos professores iniciantes: Tendência e prática investigativa no espaço universitário. Educação. 2010;33(3):189-97.

2. de Aguiar Isaia SM, Bolzan DPV. Formação do professor do ensino superior: Um processo que se aprende? Educação. 
2004;29(2):121-33.

3. Bolzan DPV, De Aguiar Isaia SM, Da Rocha Maciel AM. Formação de professores: A construção da docência e da atividade pedagógica na educação superior. Diálogo Educ. 2017;13(38):49-68.

4. de Medeiros AMS. Docência no ensino superior: dilemas contemporâneos. R. Faced. 2008;12(12):71-87.

5. Zabalza MA. O ensino universitário: seu cenário e seus protagonistas. Porto Alegre: Artemed. 2004.

6. Gatti BA. Pesquisar em educação: Considerações sobre alguns pontos-chave. Diálogo Educ. 2006;6(19):25-35.

7. Nóvoa A. Nada substitui o bom professor. Desafios do trabalho do professor no mundo contemporâneo São Paulo: SINPRO. 2007.

8. Farias CML, Carvalho RB, Liber LP, Belotti L, Dos Santos Pacheco KT. Pensamento crítico e a formação de profissionais em odontologia: Uma revisão narrativa da literatura. Rev ABENO. 2016;16(1):73-87.

9. Cunha M, Isaia S. Professor da educação superior. Enciclopédia de Pedagogia Universitária-Glossário. 2006;2:349-406.

10. Neves CEB. Desafios da educação superior. Sociologias. 2007;19(17):14-21.

11. Follmann Freire LI, Fernandez C. O professor universitário novato: Tensões, dilemas e aprendizados no início da carreira docente. Ciênc Educ. 2015;21(1):255-72.

12. Bardin L. Análise de conteúdo. Lisboa: Edições 70. 1977.

13. Santos Filho JCD. Profissão acadêmica e scholarship da docência universitária: os múltiplos papéis do profesor universitário. Rev Iberoam Educ. 2010; 61(4):1-11

14. Masetto MT, Gaeta C. Os desafios para a formação de professores do ensino superior. Rev Triang. 2016;8(2):4-13.
15. Huberman M. O ciclo de vida dos professores in: Nóvoa A. Vidas de professores Porto: Porto Editora. 1995:3161.

16. Guarnieri MR. O início na carreira docente: Pistas para o estudo do trabalho do professor. In: Guarnieri MR. Aprendendo a ensinar: o caminho nada suave da docência2 ed Campinas: Autores Associados. 2005.

17. Lisita V. Didática e formação de professores: Um estudo sobre as possibilidades da reflexão crítica [tese]. São Paulo: Universidade de São Paulo; 2006

18. Pimenta SG, Lima MSL. Estágio e docência. 4a . São Paulo: Cortez; 2009.

19. Dumêt Fernandes J, Ferreira SL, La Torre MP, de Oliveira Santa Rosa D, Costa HO. Estratégias para a implantação de uma nova proposta pedagógica na escola de enfermagem da Universidade Federal da Bahia. Rev Bras Enferm. 2003;56(4):392-5.

20. Scherer ZAP, Scherer EA, Pimenta Carvalho AM. Reflexões sobre o ensino da enfermagem e os primeiros contatos do aluno com a profissão. Rev Latino-Am Enfermagem. 2006;14(2):285-91.

21. Botomé SP, Kubo OM. Responsabilidade social dos programas de pós-graduação e formação de novos cientistas e professores de nível superior. Interação. 2002;6(1):81110.

22. Aguiar Isaia SMD, Pires Vargas Bolzan D. Compreendendo os movimentos construtivos da docência superior: Construções sobre pedagogia universitária. Linhas Críticas. 2008;14(26):43-59.

23. Franco A. Didática: Uma esperança para as dificuldades pedagógicas do ensino superior? Práxis Educ. 2013;9(15):147-66.

24. Charlot B. Da relação com o saber às práticas educativas: Cortez Editora; 2016. 
25. Lazzarin HC, Nakama L, Cordoni Júnior L. Percepção de professores de odontologia no processo de ensino-aprendizagem. Ciênc Saúde Colet. 2010;15(1):1801-10.

26. Oliveira ESGO. O "mal-estar docente" como fenômeno da modernidade: Os professores no país das maravilhas. Ciências \& Cognição. 2006;7(1):27-41.

27. Esteve JM. O mal-estar docente: A sala de aula e a saúde dos professores. Bauru: Edusc. 1999:116-33.

28. Martinez MC. As relações entre a satisfação com aspectos psicossociais no trabalho e a saúde do trabalhador. São Paulo. 2002.

29. Goldberg MaA. Avaliação de competência no desempenho do papel de orientador educacional. Cad Pesqui. 2013 (11):21-60.

30. Haydt RCC. Curso de didática geral: $1^{\mathrm{a}}$ Edição-São Paulo: Ática; 2011.

31. Candau VM. Rumo a uma nova didática. Rumo a uma nova didática: Vozes; 2003.
32. Langhi R, Nardi R. Trajetórias formativas docentes: Buscando aproximações na bibliografia sobre formação de professores. Alexandria. 2012;5(2):7-28.

33. Santos SCD. O processo de ensinoaprendizagem e a relação professor-aluno: Aplicação dos "sete princípios para a boa prática na educação de ensino superior". Cad Pequi Adm. 2010;8(1):69-82.

34. Ferreira ABDH. Novo dicionário da língua portuguesa: Nova fronteira; 1986.

35. Perrenoud P. Avaliação: da excelência à regulação das aprendizagens - entre duas lógicas: Artmed; 1999.

Correspondência para:

Bianca Medeiros Maran

e-mail: medeiros.bianca@hotmail.com

Engenharia 464, Universitário

85819-190 Cascavel/PR 